\title{
O ENSAIO NA CRÍTICA LITERÁRIA CONTEMPORÂNEA
}

Rachel Esteves Lima UFMG

RÉSUMÉ

Ce travail a pour but l'analyse de quelques caractéristiques de l'essai en tant que genre littéraire, selon la définition de Theodor W. Adorno, aussi bien que vérifier son emploi dans le texte de Walter Benjamin et dans la critique littéraire contemporaine. 
Procedendo a uma análise comparativa entre as proposições básicas de Walter Benjamin e do jovem Lukács, Rainer Rochlitz' releva o caráter ensaístico da obra dos dois críticos, em oposição ao neo-kantismo positivista dominante na crítica literária da época. À rigidez sistemática do pensamento oficial, que tinha como princípio a objetividade na análise da produção cultural, o primeiro Lukács e Benjamin assumem em seus escritos a impossibilidade de dissociação entre sujeito e objeto na análise e o caráter histórico da produção e recepção de qualquer obra. Nesse sentido, o próprio gênero escolhido para dar forma a suas idéias, o ensaio, reproduz os traços da provisoriedade e da abertura ao novo.

Considerando os conteúdos de verdade como "históricos em si mesmos" , o ensaio relativiza o que afirma, não se prendendo a nenhum apriorismo teórico e nem se instalando, definitivamente, sobre uma posição conquistada, mas, ao contrário, se colocando sempre em atitude autoreflexiva, em processo de constante atualização.

De acordo com Benjamin, a incompletude é inerente à obra de arte, cabendo à crítica muito mais o papel de suplementá-la do que o de julgá-la. Sendo assim, abole-se a hierarquia existente entre uma e outra, que passam a se relacionar em função de complementaridade. Caberia à crítica, como autoconsciência da obra, revelar a sua intenção, contribuindo para o seu aperfeiçoamento, levando-a à consciência de si $^{3}$. Evidentemente, a plena concretização desse objetivo é inalcançável, uma vez que a abertura ao movimento da história confere também ao texto crítico um caráter de inesgotabilidade do sentido. A tarefa da crítica coincide, pois, com a definição de ensaio formulada por Adorno, que consiste em vê-lo basicamente como "sobreinterpretação" , ou seja, como a tentativa de uma nova leitura de um texto, em suas relaçōes com o contexto sempre em mutação.

O método utilizado na crítica benjaminiana consiste na impossibilidade de dissociar o conteúdo temático da obra literária com a forma que o objeto de análise apresenta. $O$ conteúdo de verdade da obra de arte, o verdadeiro interesse do crítico, torna-se mais relevante na medida

1. ROCHur, 1981. De lo philosolie comme critique littéraise: Wolter Benjomin et le jeune Lukócs.

2. ADORNO, 1986. 0 ensoio como formo, p. 175.

3. C. KOTHE, 1976. p. 22

4. ADORNO, 1986 op. cit. p. 168

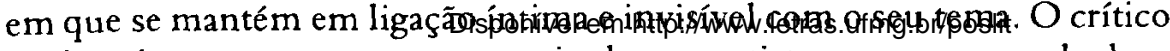
se situaria, portanto, entre o pesquisador e o artista, uma vez que ele deve fazer com que a beleza do objeto se manifeste, atingindo "o ponto mais alto de sua intensidade luminosa" . Contra a falsa objetividade totalizante da crítica tradicional, Benjamin repõe a categoria histórica como elemento preponderante na análise das obras literárias e a subjetividade inerente a toda interpretação. Como afirma Adorno, "ele queria restaurar tudo o que o espírito de acomodação e de autoconservação proibem no prazer, em que os sentidos e o intelecto se cruzam"6

Rochlitz lembra que os ensaios de Benjamin sobre Krauss, Kafka e Brecht se constituem como auto-retratos, textos em que a subjetividade benjaminiana se expressa até mesmo como uma defesa ante o momento histórico que ameaça a integridade do ser. A situação político-econômica da Alemanha, a partir do final dos anos 20 , impede que a crítica se furte a assumir uma posição diante da crise que se impunha. O homme-de-lettres vê-se, nesse momento, proletarizado e obrigado a situar-se no "combate"que se travava. Daí a impossibilidade de se manter uma atitude contemplativa, distante e apolítica diante dos textos literários, como ocorria com os críticos tradicionais: "l'anéantissement polémique de l'objet menaçant est devenu une mesure d'hygiène"

O exemplo benjaminiano mostra-se paradigmático em relação à atual situação da crítica literária brasileira, que agora começa a despir-se da rigorosa aparência de objetividade, em que se baseavam os estudos que privilegiavam, por um lado, o aspecto formal da obra de arte e, por outro, o elemento social como performador da obra literária. A volta do sujeito à cena de leitura torna-se uma reivindicação no sentido de desmitificar o caráter totalizante da crítica que se apoiava em critérios definidores do conceito de literariedade, sejam eles determinados por uma estrutura formal de composição da obra, ou pela relação reflexiva entre contexto e texto literário. Nesse sentido, a proposta de uma postura teórica sustentada pelo triângulo "vida-arte-poesia", estabelecida por Boris Schnaiderman em seu ensaio "Vivência pessoal e reflexão teórica", aponta para a necessidade de se produzir um texto crítico em que o sujeito não se omita ou se camufle sab a pretensa noção de cientificidade, mas se exponha numa posição em que política e estética se fundem.

\section{BENIAMIN, 1984, P. 54}

6. ADORNO, 1986. Corocterizoçấo de Walter Benjamin, p. 189

7. ROCHLIR, 1981.

8. SCHNAIDERMAN, 1988. Vivêncio pessool e reflexóo teórico.

\section{REVISTA DE ESTUDOS DE LITERATURA}

Belo Horizonte, v. 3, p. $35-41$, out. 95 
Disponível em http://www.letras.ufmg.br/poslit

Não à crítica impressionista, mas não também à crítica puramente formal ou sociológica. O que se pretende é a vinculação do contexto à produção e recepção do texto literário, sem que este seja visto como um reflexo daquele, mas como um objeto que mantém uma relativa autonomia, pois liga-se, necessariamente, ao solo em que foi produzido, mas que também depende de interpretaçōes que lhe conferem significados diversos, determinados por cada olhar que lhe é lançado, em momentos específicos. A crítica literária adquire, então, a função de suplementar a obra literária, como foi enunciado anteriormente, devendo, para isso, resgatar o prazer da leitura, tanto do texto literário propriamente dito, quanto do seu comentário. A consciência da impossibilidade de se alcançar a totalidade ou o Universal faz com que a crítica se libere para buscar no fragmentário e no particular um sentido que possa conduzir ao conhecimento da obra através de uma relação pessoal com o texto que, em relação com outros textos, vão constituindo a vivência literária contemporânea.

O ensaio tem sido a forma privilegiada no cenário da crítica literária brasileira na atualidade, e até mesmo nos textos que cobrem a área de ciências humanas em geral. Através dele, busca-se a proximidade com o leitor, numa prosa que se coloca entre a teoria e a linguagem artística, da qual extrai inúmeros procedimentos que visam tornar a leitura um ato prazeroso de absorção de conhecimento, deixando de dirigir-se ao leitor especializado, para encontrar-se com o leitor comum. Proliferam nos suplementos literários ensaios que não mantêm, necessariamente, uma relação entre si, mas que, justapostos, objetivam a ampliação do interesse do leitor, que trava contatos com uma grande diversidade de assuntos, extrapolando, assim, o seu interesse específico, colocando-se em relação interdisciplinar com outros campos antes desconhecidos. $\mathrm{O}$ que, em princípio, se constitui como fragmentário, acaba apontando para uma visão mais global, em que o confronto de idéias funciona como agente propiciador de um alargamento da percepção individual.

A presença de uma forte diç̧ão ensaística na produção de outros discursos que, tradicionalmente, pressupunham uma carga ainda maior de objetividade e rigor científico que a crítica literária, como é o caso do registro histórico e até mesmo do psicanalítico, sugere a ocorrência de um processo de redefinição do lugar que o sujeito ocupa na enunciação de um "saber" e de um questionamento acerca da legitimidade desse próprio saber.

O processo de desconstrução do sujeito, empreendido por filósofos como Derrida, Deleuze, Foucault, Bourdieu e Althusser, a partir, principalmente, da visão nietzscheana que desconhece a existência de fatos,
Disponível em http://www.letras.ufmg.br/poslit

fixando-se apenas nas interpretações, vai provocar nas ciências humanas um deslocamento da ênfase conferida, até há pouco tempo, ao acontecimento ou à obra em si, passando a recair sobre as condições de produção do discurso sobre tal acontecimento ou obra. Rompe-se com conceitos baseados nas noçōes de causalidade e linearidade temporal, características de uma visão mecânica do funcionamento social, buscandose enfatizar não mais as semelhanças, mas as diferenças, as especificidades de cada cultura.

A emergência de uma nova temporalidade, baseada nos cortes e rupturas, na descontinuidade, surge como uma recusa à noção de progresso, de evolução histórica. Observa-se a ocorrência de uma nova relação com o passado, que agora não pode mais ser visto simplesmente como uma etapa necessária ao ciclo evolutivo da humanidade. Tenta-se trazer à tona aquilo que foi recalcado no discurso histórico dominante, ou, no dizer de Michel De Certeau, trabalha-se com as fissuras, as lacunas que constituem o indivíduo enquanto ser histórico. Abalada a crença no progresso, detectada a "decepção da modernidade", o indivíduo reage através da busca do conhecimento de si próprio, procurando ver no passado não mais uma mera explicação de seu presente, mas fazendo com que as duas temporalidades coexistam numa perspectiva dialética, em que importa analisar os "lugares históricos dos recalcamentos" discurso e de práticas regulamentadoras da convivência socializada, baseadas na repressão do corpo. Como desejava Benjamin, o historiador deve procurar manter uma "experiência única com o passado"ll, para acordar os mortos, despertando com eles os sonhos que ficaram para trás.

O reconhecimento da impossibilidade de constituição de um discurso que trata do homem e de sua organização social e cultural através da ciência positivista jogará por terra o privilégio do acontecimento, visto como elemento estruturador do discurso que o engendra. A ênfase passa a recair sobre o fragmento, em oposição à causalidade própria ao universalismo das concepções positivistas. Analisando cada aspecto da cultura em sua singularidade, o historiador, desprovido de arquivos e desconfiando da "autenticidade" do documento tem que lançar mão de uma estratégia de elaboração textual que não tem como fugir do regime

9. Cf. ARIÉS et alii, 1986. p. 24

10. LE GOFF, 1986. p. 100.

11. BENJAMIH, 1985. Sobre o conceito de Histório, p. 231 
Disponível em http://www.letras.ufmg.br/poslit

da ficção: "ficção científica", como quer De Certeau', uma mistura que contém elementos pertencentes ao domínio da ciência e da fábula, restituindo à História o seu estatuto de espetáculo, de uma prática retórica Definidos os limites, a partir dos dados levantados, dos restos documentais avaliados, o historiador passa à construção da narrativa que sustentará suas conclusōes. Depende de sua habilidade em lidar com a argumentação, com a encenação do texto propriamente dito, a sua autoridade profissional. A revalorização de um historiador como Michelet, por algum tempo considerado de menor importância pelo envolvimento subjetivo no discurso histórico, restaura a ligação existente entre a ficção e a ciência, entre o sujeito e o discurso por ele produzido. O ensaio se impõe, então, como a forma adequada à manifestação de um conhecimento que se mostra transitório e vinculado ao seu agente produtor.

Se o ensaio tem se mostrado a forma mais adequada à transmissão do discurso histórico, que pressuporia um maior rigor em sua elaboração, no que se refere ao discurso da crítica literária, observa-se também um revigoramento de sua prática, com uma maior liberdade para a exposição do sujeito que a realiza. Raros são, ainda, os exemplos daqueles que têm se proposto revelar-se explicitamente no texto crítico, como quer Schnaiderman, mas é certo que uma série de recursos tem sido utilizada no sentido de resgatar a presença do sujeito e de enunciar uma relação de prazer com o objeto de estudo, e não mais uma relação de dominação.

A atenção conferida atualmente à preparação da perigrafia numa obra de crítica literária denuncia uma preocupação quanto à imagem que o autor quer passar acerca de si mesmo e também um desejo de envolver, de seduzir o leitor, prendendo-o nas malhas da enunciação, através dos ornamentos textuais. Compagnon afirma, neste sentido, que a perigrafia "est une scénographie qui met le texte en perspective, et l'auteur en est le centre"13. Testemunha do controle exercido pelo autor sobre o texto, a perigrafia evidencia, atualmente, uma mudança de intenção por parte do autor, antes preocupado em documentar e legitimar sua autoridade, hoje, consciente da parcialidade e fragmentaçăo de todo saber, interessado em perenizar o que se mostra sempre transitório.

Nesse sentido, a estratégia de sedução do texto crítico pressupõe um cenário embelezado por epígrafes que agora são citaçōes de textos de ficção, em detrimento daqueles dos grande teóricos, amplamente citados

12. DE CERTEAU et olii, 1986. p. 33.

13. COMPAGNON, 1979. p. 328
Disponível em http://www.letras.ufmg.br/poslit

nos trabalhos dos anos 70 e 80 , como caução para a sua objetividade e rigor acadêmico. O tratamento conferido às referências bibliográficas e às citações propriamente ditas também se alterou significativamente. Sustentáculos da autoridade do autor, durante muito tempo destacadas e utilizadas em profusão, as citações passam a compor o texto como um todo, incorporadas como o dito e não mais como o inter-dito.

Se antes a autoridade se baseava num tom didático, num encadeamento causal e explicativo, nota-se, atualmente, a ocorrência de uma busca da narratividade, baseada em relações coordenativas, que enriquecem o texto pela justaposição de elementos diversos, em processo de interação interdisciplinar. Rompe-se com a linearidade dos estudos que se baseavam numa visão diacrônica da história literária, que passa a ser produzida em termos sincrônicos e, portanto, necessariamente fragmentários. Trabalhando com obras do passado que se mostrem imprescindíveis à interpretação do presente, sem no entanto deter-se numa linha evolutiva, o crítico literário vê-se obrigado a assumir ainda mais sua subjetividade/arbitrariedade no tratamento da obra literária, pisando num solo escorregadio, que abala suas certezas e convicçōes. A busca de um sentido se dá num universo complexo e multifacetado, em que o saber acumulado é colocado em xeque, assim como as instituições nas quais é produzido. O crítico se vê como o cidadão ou o leitor comum, pois, como lembra Silviano Santiago, "afirma a sua certeza precária, sabendo ser ela apenas um tijolo. Ou um voto. Voto é também desejo"14.
14. SANTIAGO, 1989. Não, nōo otirem em Sotio.
REVISTA DE ESTUDOS DE UIIERATURA Belo Horizonte, $y, 3$, p. $35-41$, out 95 


\section{REFERÊNCIAS BIBLIOGRÍFICAS}

ADORNO, Theodor W. O ensaio como formo. In: COHN, Gabriel (Org.) Theodar Adomo. São Poulo: Ática, 1986. (Grandes cientistas sociois, 54)

ADQRNO, Theodor W. Coracterizocono de Wolter Benjamin. In: idem.

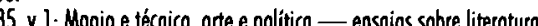

Origem do dromo barroco alemöo. Säo Paulo: Brosiliense, 1984.

COMPAGNON, Antoin

DE CERTEAU, Michel et olii. A Novo Historio. lisboo: Edisées 70,1986

KOTHE, Flóvio R. Paro ler Beniomin Rio de Joneiro: Froncisco Alves 1976.

IF GOFF. Jocques. Refexēes sobre a Historio Lisboo: Edicōes $70,1986$.

ROCHLIIZ, Roiner. De lo philosolie comme critique littéroire: Walter Benjomin et le jeune Lukérs. In: Revve D'Esthétique. Nouvelle série, n. l, 1981.

SANTIAGO, Silviono. Nöa, nõo otirem em Sotio. in: Idelias livros, ono I, n. 160, 27/out/B9.

SCHNAIDERMAN, Boris. Vivêncio pessool e reflexōo teórico. In: Anois do I Congresso Abrolic. Porto Alegre: Abrolic, 1988.

\section{DO FLORILÉGIO À ANTOLOGIA DA POESIA BRASILEIRA DA INVENÇ̃O: UMA REFLEXÃO SOBRE O PARADIGMA DA HISTÓRIA DA LITERATURA BRASILEIRA}

Luiz Roberto Velloso Cairo UNESP

\section{ABSTRACT}

This paper aims to discuss the Brazilian Literary History model, a polemic issue, which concerned the romantic and realistic Brazilian criticism and still arouses the interest of contemporary criticism. 